\title{
Proceeding
}

Supplementary Issue: Autumn Conferences of Sports Science. Costa Blanca Sports Science Events, 18-19 December 2020. Alicante, Spain.

\section{Football the performance level of athletes with disabilities for the "fourth category" 7-a-side championship}

\author{
DANILO D'ANDREA 14 , RAFFAELE SCURATI², RICCARDO IZZO³, PIETRO LUIGI INVERNIZZI², \\ TIZIANA D'ISANTO ${ }^{1}$ \\ ${ }^{1}$ University of Salerno, Italy \\ ${ }^{2}$ Department of Biomedical Sciences, University of Milan, Italy \\ 3 University Carlo Bo of Urbino, Italy
}

\begin{abstract}
The work presented is important because it allows us to demonstrate the actual benefits, in this case concerning the physical sphere, of motor and sports practice on athletes with various disabilities. The study was conducted on 10 athletes belonging to a football school, each of whom has various types of diagnosed disabilities such as down syndrome, autism spectrum disorder, intellectual-cognitive disability, or motor disability, characterized by low functionality. Considering the problem, which is to adapt the performance level of the athletes to the performance model required for the "Fourth Category" 7-a-side football championship for disabled people, obtained by comparing it with the same, however, referred to 11 -a-side football, they underwent an 8-week mesocycle of training, with the administration of motor evaluation tests both at the beginning and at the end of this period. The test results will then be compared with the statistical $t$ test technique for dependent samples. From this comparison, significant differences emerged about endurance and sprint tests, and insignificant differences for the standing long jump. The conclusion therefore leads us to state that, through training, it is possible to increase the parameters of the performance level of disabled athletes to make them conform to the performance model and physiological commitment that the Fourth Category Championship requires.

Keywords: Disabled people football player; Performance level; Field test.

\section{Cite this article as:}

D'Andrea, D., Scurati, R., Izzo, R., Invernizzi, P.L., \& D'Isanto, T. (2021). Football the performance level of athletes with disabilities for the "fourth category" 7-a-side championship. Journal of Human Sport and Exercise, 16(2proc), S743-S751. doi:https://doi.org/10.14198/jhse.2021.16.Proc2.60

Corresponding author. University of Salerno, Italy. https://orcid.org/0000-0002-0315-4772

E-mail: d.dandrea5@studenti.unisa.it

Abstract submitted to: Autumn Conferences of Sports Science. Costa Blanca Sports Science Events, 18-19 December 2020. Alicante, Spain.

JOURNAL OF HUMAN SPORT \& EXERCISE ISSN 1988-5202

(c) Faculty of Education. University of Alicante

doi:10.14198/jhse.2021.16.Proc2.60
\end{abstract}




\section{INTRODUCTION}

The study I dealt with will deal with the discipline of 7 -a-side football for athletes with intellectual-relational, motor, cognitive and psychiatric disabilities. This discipline, since 2019, has been recognized at a federal level with the creation of the Paralympic and Experimental Football Division (DCPS), which belongs to the FIGC. Despite this, the 7-a-side football tournaments of the so-called "Fourth category" were born as early as 2016, taking as a reference point from a regulatory point of view the provisions in place for 11 -a-side football of the FIGC, modifying it based on what are the peculiarity of 7-a-side football for all, which however is not a federally recognized discipline. The numerous differences that can be highlighted as regards the regulation, do not exist if we consider the fundamentals of the two disciplines. In both 11-a-side football for able-bodied and 7-a-side football for the disabled, individual fundamentals can be shooting, passing, dribbling, ball domination, header, stop and others. The team fundamentals, on the other hand, can be the triangle, the pressing, the man or zone defence and also others (Esposito \& Raiola, 2020). The general objective of this study is to define the performance model, from a quantitative point of view, of athletes with disabilities practicing the discipline of 7 -a-side football, both before and after a specific training mesocycle (Halouani, et al., 2017). To define the performance model of this discipline, it is useful to recall some information regarding the same performance model, referring however to 11-a-side football, accentuating any differences. In 11-a-side football, the Football Performance, from an energetic point of view, can be defined as alternating aerobic / anaerobic commitment, i.e., physiologically it is based on the regular alternation of sub-aerobic phase (commitment lower than the maximum aerobic Capacity), aerobic (at the limit of Aerobic Power), anaerobic (efforts that engage the metabolic systems in the absence of Oxygen), and finally rest (Raiola et al., 2020; Rizvandi et al., 2019). We can find moments of high commitment and moments of low commitment, alternate or null. In moments of high commitment there is a considerable demand for energy and therefore the muscles consume a lot of ATP (Adenosine triphosphate - energy in practice) for every second. They get it from different sources: from preformed ATP; from phosphocreatine; from oxygen; lactacid by the anaerobic mechanism. Therefore, in the phases of intense effort, most of the ATP is produced not using oxygen, but creating a debt of oxygen, alactic acid (there is no accumulation of lactic acid) or lactacid (accumulation of lactic acid). In times of little or no commitment, these oxygen debts are paid off. Recovery is made possible by the fact that the oxygen reaching the muscles is greater than what the muscles need at that moment, and the surplus of oxygen is used to reform phosphocreatine, restore oxygen to myoglobin, eliminate lactic acid (Kilding et al., 2008). Football, like all team sports, is characterized by "intermittent" movements, that is performed at different speeds with prolonged pauses and combined with a whole series of specific motor acts (jumps, backwards runs, dribbling, throws, etc.). In physiology applied to sport it is classified as "an activity with alternating" aerobic-anaerobic characteristics (Ceruso et al., 2019). This derives from the fact that the game requires, in 90 minutes, a continuous alternation of metabolic commitments (aerobic, anaerobic, lactacids and alactacids), the application of various types of strength and complex specific coordination skills (Raiola, Tafuri, 2015). On average, a player during a game changes activities every 4-6 seconds, resulting in the performance of about 1300 motor patterns during the game, of which about 200 are highly intense. In addition to this, it has been estimated that each player performs 1000 to 1400 speed changes and 700 to 800 changes of direction, and this assumes that a player has great explosive strength (Izzo et al., 2020). The alternating explosiveness and speed require a so-called "short resistance rather than specific endurance qualities". The overall workload imposed by the match is significant, in fact the average heart rate of the race oscillates between $80 \%$ and $90 \%$ of the maximum heart rate (Rosch et al., 2000). Thanks to the use of match analysis, it is now known that a high-level footballer travels between 9 and $12 \mathrm{~km}$ during a match (Altavilla, 2020). However, this total distance can be divided into various levels of intensity where: 2200 - 2400 meters are travelled at high intensity with a speed greater than $15.0 \mathrm{~km} / \mathrm{h}$; 850 -950 meters are travelled at very high intensity with a speed greater than $19.8 \mathrm{Km} / \mathrm{h} ; 250$ - 350 meters 
are covered in sprints with speeds greater than $25 \mathrm{~km} / \mathrm{h}$. Analysing in the detail every single role we can easily realize that the winger (both defensive and offensive) and midfielders cover the greatest distance, which most often exceeds $11 \mathrm{~km}$ (Altavilla et al., 2017). During a match, a sprint occurs approximately every 90 seconds, each lasting 2-4 seconds on average. Sprints make up 1-11\% of the total distance covered during a match. Regarding $\mathrm{VO}_{2 \max }$, no $100 \%$ accurate and valid studies have yet been made, but the most reliable study, conducted by Ogushi et al. Using the equipment of Douglas bags (heavy $1200 \mathrm{~g}$ ), he detected a VO 2 of 35 and $38 \mathrm{ml} / \mathrm{kg} / \mathrm{min}$ in the first half and of 29 and 30 in the second, which correspond respectively to $56-61 \%$ and $47-49 \%$ of the maximum oxygen consumption (Raiola, Tafuri, 2015). As for the performance model in 7-a-side football for the disabled, unfortunately there are no studies in the literature that provide exact data on the physiological commitment of athletes in this discipline, so it is necessary to consider the above data regarding 11-a-side football and adapt them to a sport which, first of all, is played in a small playing field and requires a shorter duration than a match (Kaczor et al., 2017). This means that certainly the physiological commitment for a 7-a-side football athlete, with or without disability, will be lower than that of an 11-a-side football athlete (Panfil \& Mazur, 2018). It will be lower in terms of $\mathrm{VO}_{2 m a x}$ commitment, since the efforts will not be excessively prolonged due to the playing field and the duration of a match; it will be lower in terms of maximum heart rate since the pace of play in football for the disabled is much less fast and frenetic, therefore with a greater presence of rest phases that tend to lower the HR $\max$ (Turs et al., 2014; Martino et al., 2019). Obviously, also from the point of view of the kilometres travelled and the number of changes in direction or speed, a substantial difference will be noticed (Cascone et al., 2020). All this does not mean that 7-a-side football for the disabled can also be considered an intermittent sport, since it too involves an alternation of medium-high intensity game phases, in relation to the characteristics of the athletes, and game phases. characterized by periods of pause and therefore of recovery (Partington \& Cushion, 2013). Considering this, it can still be classified as an activity with alternating aerobic-anaerobic characteristics. In the analysis of a 7-a-side football match for the disabled, the level and pace of play is much lower than that of 11-a-side football not only for the reasons of field size or duration of the match, but also and above all for the characteristics of the athletes (Joo et al., 2016). In fact, in footballers with intellectual-cognitive disabilities, for example, the decision-making mechanism and therefore the execution of a technical gesture takes much more time than in the same situation in football with non-disabled athletes and this obviously lowers what can be game intensity and significantly slows the pace of play (Invernizzi et al., 2020). By combining the information reported regarding the performance model with the specific objective of our study, which is to verify a possible increase, through a specific training mesocycle, of the characters indicated above, we will have to subject the athletes to validated and standardized tests, such as the hut test, the Pizzolato test or the long jump test, both before and after the defined training period. Subsequently we will compare the results of the two surveys using the statistical method (MacDougall et al., 1991). These two tests will allow us to detect and compare data regarding $\mathrm{VO}_{2 \max }, \mathrm{HR}_{\max }$ and explosive force that are indicated in the performance model (Raiola, Altavilla, 2020). The training sessions that will be offered to our athletes are both the solicitation to learn and improve basic motor patterns, and what concerns the practice of football such as shooting, passing, dribbling and other basic skills, accompanied by exercises regarding the improvement of speed, strength, and endurance (Di Palma et al., 2017).

\begin{abstract}
Aim
The objective of this study, therefore, is to verify that an 8-week mesocycle of specific training can bring results in terms of $\mathrm{VO}_{2 \max }$, speed in the sprint linked to endurance and explosive strength, given that the fulcrum of the previously analysed performance model is represented by the kilometres covered during a match and the number of sprints and changes of speed or direction performed. The null hypothesis $(\mathrm{HO})$ is therefore posited that at the end of the mesocycle under consideration there will be no increase or decrease in these physiological characteristics, or that they exist but are not significant, and as an alternative
\end{abstract}


hypothesis $(\mathrm{H} 1)$ that which at the end of mesocycle the physiological changes instead will occur to such an extent $d$ to have the certainty that they are due to the training methodology.

Materials and methods

\section{Participants}

The study was conducted on 10 athletes belonging to a football school, each of whom has various types of diagnosed disabilities such as down syndrome, autism spectrum disorder, intellectual-cognitive disability, or motor disability. These athletes were not grouped according to age, which in this case varies from 10 to 17 years but based on their functional capacity and their skills in the fundamentals of football. In this case, the athletes who were the subject of this study fall into the medium-low functionality category, which includes children and teenagers who have deficits in some basic motor patterns and a poor command of football skills.

\section{Organizations}

These players were subjected to an 8-week training mesocycle in which an attempt was made to intervene on endurance ( $\mathrm{VO}_{2 \max }$, Pizzolato's 7-minute test), speed (hut test), and explosive strength (jump test). long when stationary). Each workout, in fact, provided at the beginning of the session both exercises that aimed at improving joint flexibility and mobility, and the strength in the legs which is essential to effectively perform the high number of changes of speed and direction that a football match requires. During each workout, then, through exercises with the ball it was also possible to aim at achieving results also in terms of improving endurance and speed. Then, in a first phase of evaluation, the athletes were subjected to 3 incoming tests: the first is the Pizzolato 7-minute endurance test (Table 1), the second is the Capanna-Sassi test that goes to evaluate the speed combined with the resistance (Table 2) and the third and the long jump test from standing to monitor the explosive force (Table 3). Pizzolato's 7-minute test (based on this specific time frame because Peronnet has shown that near the maximum oxygen consumption an athlete is able to maintain the effort for about 7 ') allows to indirectly measure the values of $\mathrm{VO}_{2 \max }$ and of $\mathrm{SAN}$, detecting the greatest possible distance that an athlete can cover in fact 7 'routes at maximum speed; provided that the test can be considered reliable, the speed must be constant for the entire duration of the effort. The Tanaka formula for calculating $\mathrm{FC}_{\max }$, on the other hand, consists in applying the following formula: 208 - (product between age and constant 0.7). The Capanna-Sassi test consists of repeating a shuttle sprint of $20+20$ meters for 6 times, with a change of direction after the first 20 meters and a recovery of 20 seconds between one sprint and another. Since in football for non-disabled people, as in football for the disabled but obviously to a lesser extent, each match is characterized by a succession of a high number of sprints, sometimes consecutive with a few seconds of recovery, it is useful to evaluate the athlete's ability. to effectively perform these sprints (repeated sprint ability) through the hut test. This definition is adapted to the football context of the more general term "resistance to speed" (Di Domenico et al., 2019). Lastly, for the standing long jump test, the subject positions himself with his toes at the edge of the long jump pit. The athlete squats by placing the feet at a distance like shoulder width. By leaning the torso forward and placing the arms backwards, the subject performs a jump with even feet trying to cover the greatest horizontal distance possible. The test is repeated three times and the distance between the jump line and the point of contact of the body closest to it is measured each time, to then take the best distance. The analysis of the results of the long jump test from standing allows to establish the explosive elastic force of the athlete's lower limbs and, if referred to previous tests, can give an estimate of the improvements or worsening of performance. The athlete will have to swing his arms to give himself momentum, then throw them forward and, bending the knees, jump forward as far as possible. The athlete will try to land simultaneously with both feet together and to keep balance. Repeat the test twice and score the best performance. The measurement will be taken from the start line to the rearmost heel landing point. The test is considered void if the athlete falls backwards or forwards on landing. 


\section{Statistical analysis}

At the end of the 8-week training mesocycle these tests were repeated, comparing the data collected with those of the incoming tests using the statistical method of the t-test, which allows us by analysing the differences between the two data series by establishing whether they are significant, with the aim of rejecting the null hypothesis and possibly accepting the alternative. The level of significance set is $p<.01$ for the Pizzolato test and $p<.05$ for the Capanna-Sassi test and for the standing long jump test. The $t$ test was then performed 3 times, one for each test, comparing the results obtained before and after the training session (Tables: $4,5,6)$

\section{RESULTS}

Table 1. Pizzolato Test Results after and before training.

\begin{tabular}{lccccccc}
\hline & \multicolumn{3}{c}{ Before training } & \multicolumn{3}{c}{ After training } \\
\hline Players & Age & $\begin{array}{c}\text { Distance } \\
(\mathbf{m})\end{array}$ & $\begin{array}{c}\mathbf{V O}_{\text {max }} \\
(\mathbf{m l} / \mathbf{k g} / \mathbf{m i n})\end{array}$ & $\begin{array}{c}\mathrm{FC}_{\max } \\
(\mathrm{BPM})\end{array}$ & $\begin{array}{c}\text { Distance } \\
(\mathbf{m})\end{array}$ & $\begin{array}{c}\mathbf{V O}_{\text {max }} \\
(\mathbf{m l} / \mathbf{k g} / \mathbf{m i n})\end{array}$ & $\begin{array}{c}\mathbf{F C}_{\text {max }} \\
(\mathbf{B P M})\end{array}$ \\
\hline Player 1 & 10 & 1210 & 35.3 & 194.7 & 1246 & 36.2 & 190.4 \\
Player 2 & 12 & 1290 & 37.4 & 191.2 & 1407 & 41.1 & 185.3 \\
Player 3 & 12 & 1245 & 36.2 & 186.6 & 1294 & 37.4 & 182.7 \\
Player 4 & 13 & 1320 & 38.6 & 189.1 & 1473 & 43.3 & 183.8 \\
Player 5 & 11 & 1222 & 35.8 & 186.3 & 1264 & 36.8 & 180.2 \\
Player 6 & 17 & 1301 & 38.0 & 195.4 & 1458 & 42.6 & 191.6 \\
Player 7 & 10 & 1243 & 36.2 & 190.5 & 1280 & 37.4 & 187.8 \\
Player 8 & 15 & 1257 & 36.8 & 191.2 & 1324 & 38.6 & 185.1 \\
Player 9 & 14 & 1325 & 38.6 & 189.1 & 1493 & 43.3 & 183.0 \\
Player 10 & 13 & 1267 & 36.8 & 184.2 & 1342 & 39.2 & 178.5 \\
\hline
\end{tabular}

Table 2. Capanna-Sassi Test.

\begin{tabular}{lcc}
\hline & Before training & After training \\
\hline Players & Circuit time $(\mathbf{s e c})$ & Circuit time $(\mathbf{s e c})$ \\
\hline Player 1 & 8.51 & 8.28 \\
Player 2 & 9.11 & 8.82 \\
Player 3 & 8.41 & 8.20 \\
Player 4 & 8.65 & 8.44 \\
Player 5 & 8.99 & 8.72 \\
Player 6 & 8.57 & 8.36 \\
Player 7 & 8.67 & 8.39 \\
Player 8 & 9.09 & 8.78 \\
Player 9 & 8.42 & 8.28 \\
Player 10 & 8.55 & 8.32 \\
\hline
\end{tabular}

Table 3. Long jump test standing.

\begin{tabular}{lcc}
\hline & Before training & After training \\
\hline Players & Jump distance $(\mathbf{c m})$ & Jump distance $(\mathbf{c m})$ \\
\hline Player 1 & 73 & 76 \\
Player 2 & 103 & 110 \\
Player 3 & 60 & 62
\end{tabular}




\begin{tabular}{lcc}
\hline Player 4 & 180 & 191 \\
Player 5 & 65 & 66 \\
Player 6 & 90 & 94 \\
Player 7 & 55 & 55 \\
Player 8 & 60 & 63 \\
Player 9 & 105 & 113 \\
Player 10 & 68 & 75 \\
\hline
\end{tabular}

Table 4. ( $\mathrm{VO}_{2 \max }$, test Pizzolato).

\begin{tabular}{lcc}
\hline & Variable 1 & Variable 2 \\
\hline Mean & 36.742857 & 39.18571 \\
Variance & 1.2441758 & 6.679780 \\
Observation & 10 & 10 \\
Overall Variance & 3.9619780 & \\
Hypothesized Mean Difference & 0 & \\
$\mathrm{df}$ & 18 & \\
Stat $t$ & -3.24706 & \\
$p(T<=t)$ one-tail & .0016026 & \\
$\mathrm{~T}$ critical one-tail & 1.7056179 & \\
$p(T<=t)$ two-tail & .0032052 & \\
$T$ critical two- tail & 2.0555294 & \\
\hline
\end{tabular}

Table 5. (Capanna-Sassi test, circuit time).

\begin{tabular}{lcc} 
& Variable 1 & Variable 2 \\
\hline Mean & 8.697 & 8.459 \\
Variance & 0.071734444 & 0.051876667 \\
Observation & 10 & 10 \\
Overall Variance & 0.061805556 & \\
Hypothesized Mean Difference & 0 & \\
df & 18 & \\
Stat $t$ & 2.140662504 & \\
$p(T<=t)$ one-tail & .023120869 & \\
$T$ critical one-tail & 1.734063607 & \\
$p(T<=t)$ two-tail & .046241738 & \\
$T$ critical two-tail & 2.10092204 & \\
\hline
\end{tabular}

Table 6. (Long jump test standing, jump distance).

\begin{tabular}{lcc}
\hline & Variable 1 & Variable 2 \\
\hline Mean & 85.9 & 90.5 \\
Variance & 1416.544444 & 1653.166667 \\
Observation & 10 & 10 \\
Overall Variance & 1534.855556 & \\
Hypothesized Mean Difference & 0 & \\
df & 18 & \\
Stat $t$ & -0.26254822 & \\
$p(T<=t)$ one-tail & .397940088 & \\
T critical one-tail & 1.734063607 & \\
\hline
\end{tabular}




\begin{tabular}{ll}
\hline$p(T<=t)$ two-tail & .795880177 \\
$T$ critical two-tail & 2.10092204 \\
\hline
\end{tabular}

\section{DISCUSSION}

From the results obtained with this statistical analysis, we highlight those that are the most important to us. Taking into consideration Table 4 referred to $\mathrm{VO}_{2 \mathrm{max}}$, we observe how the value of $p$ for the two-tailed test is equal to .0032 and this establishes that the differences between the two measurements are extremely significant for $p<.01$. In relation to Table 5 referring to the Capanna-Sassi test, however, the resulting $p$ of the two-tailed test is equal to .046 and this means that the differences between the two measurements are slightly significant for $p<.05$. An emblematic case, on the other hand, represents the results regarding Table 6 referring to the long jump test from standing, from which we can see that the resulting $p$ of the two-tailed test corresponds to .795 , which means that the differences between two measurements are not significant for $p<.05$. These results allow us to be able to reject $\mathrm{H} 0$ and accept $\mathrm{H} 1$ only in cases of improved endurance and speed, while in the case of explosive force we are unable to do so. For the first two cases, therefore, we can establish, according to what is the objective of our study, that the differences between the data acquired before and after the training methodology taken into consideration, are significant enough to be attributed to training. same. In the third case, however, although improvements were still found at the end of the training mesocycle, they are not marked enough to be attributed with certainty to training (Gaetano \& Rago, 2014). Translating these results into practical terms, we can underline that the study we conducted proved useful for two of the three goals we set for ourselves. In fact, we found a high significance in the increase in the values of $\mathrm{VO}_{2 \max }$ and speed in the execution of the path and in the decrease in the values of $\mathrm{FC}_{\max }$, such that we can attribute them, with a margin of error of $1 \%$ in the case of $\mathrm{VO}_{2 \max }$ and $5 \%$ in the case of speed, to the benefits produced by training (Giovanni et al., 2020). These results are consistent with the study in the literature cited in the introduction.

\section{CONCLUSIONS}

In conclusion, we can say that by working constantly and according to a precise training methodology on athletes with different disabilities, for an indicative period of 8 weeks, we are able to obtain results in terms of improving the conditional skills of athletes, in order to standardize the their characteristics to what is the performance model of the discipline they are going to practice and "prepare" them for the physiological commitment it requires, in such a way as to make their practice as effective as possible. A final consideration must be observed, however, for the non-significant confirmation of the improvement as regards the explosive force. This result can be traced back not so much to the ineffectiveness of the training methodology, as to the duration of the mesocycle, which if he had foreseen a longer training period would probably have led to a significant result also in this respect. This can be said for two reasons: the first is that however, even if minimal, we could see improvements between the pre- and post-training evaluations; the second is that it is more difficult to work in such a short time on the muscle strength of athletes with disabilities, especially in the subjects of this study who have the characteristics of low-medium functionality and who have never been solicited from this point of view before this study.

\section{REFERENCES}

Altavilla, G. (2020) Energetic cost in the different running conditions in team sport for the educational teaching method, Sport Science, 14 (1), pp. 17-20. 
Altavilla, G., Riela, L., Di Tore, A.P., Raiola, G. (2017) The physical effort required from professional football players in different playing positions. Journal of Physical Education and Sport, 17 (3), art. no. 200, pp. 2007-2012.

Cascone, C., De Cesare, G.R., D'Elia, F. (2020). Physical education teacher training for disability, Journal of Human Sport and Exercise, 15, pp. S634-S644. https://doi.org/10.14198/ihse.2020.15.Proc3.16

Ceruso, R., Esposito, G., D'elia, F. (2019) Coordination attached to the qualitative aspects of football, Journal of Physical Education and Sport, 19, art. no. 260, pp. 1773-1776.

Di Domenico, F., D'isanto, T., Raiola, G. (2019) Role of speed and agility in the effectiveness of motor performance, Journal of Physical Education and Sport, 19, art. no. 271, pp. 1836-1842.

Di Palma, D., Raiola, G., Tafuri, D. (2017) The strategic contribution of sport to the management of diversity, Sport Science, 10 (1), pp. 40-43.

Esposito, G., Raiola, G. (2020) Monitoring the performance and technique consolidation in youth football players, Trends in Sport Sciences, 27 (2), pp. 93-100.

Gaetano, R., Rago, V. (2014) Preliminary study on effects of hiit-high intensity intermittent training in youth soccer players, Journal of Physical Education and Sport, 14 (2), pp. 148-150.

Giovanni, E., Francesca, D., Gaetano, R. (2020) A method to promote the Development of intelligence and game skills in youth football, Teoria ta Metodika Fizicnogo Vihovanna, 20 (3), pp. 142-148. https://doi.org/10.17309/tmfv.2020.3.03

Halouani, J., Chtourou, H., Dellal, A., Chaouachi, A., \& Chamari, K. (2017). Soccer small-sided games in young players: rule modification to induce higher physiological responses. Biology of sport, 34(2),163. https://doi.org/10.5114/biolsport.2017.64590

Invernizzi, P. L., Signorini, G., Bosio, A., Raiola, G., \& Scurati, R. (2020). Validity and Reliability of SelfPerception-Based Submaximal Fitness Tests in Young Adult Females: An Educational Perspective. Sustainability, 12(6), 2265. https://doi.org/10.3390/su12062265

Izzo, R., Rossini, U., Raiola, G., Cejudo Palomo, A., Hosseini Varde'l, C. (2020) Insurgence of fatigue and its implications in the selection and accuracy of passes in football. A case study, Journal of Physical Education and Sport, 20 (4), art. no. 269, pp. 1996-2002.

Joo, C. H., Hwang-Bo, K., \& Jee, H. (2016). Technical and physical activities of small-sided games in young Korean soccer players. Journal of strength and conditioning research, 30(8), 2164-2173. https://doi.org/10.1519/JSC.0000000000001319

Kaczor, M., \& Duda, H. (2017). The impact of the creative model in teaching football on professional knowledge and effectiveness of players aged 12 and 13. Journal of Kinesiology and Exercise Sciences, 80(27), 27-34.

Kilding, A. E., Tunstall, H., \& Kuzmic, D. (2008). Suitability of FIFA's "The 11" training programme for young football players-impact on physical performance. Journal of sports science \& medicine, 7(3), 320.

MacDougall, J.D., Wenger, H.A., \& Green, H.J. (1991). Physiological testing of the high-performance athlete (2nd ed.). Campaign: Human Kinetics.

Martino, L., Fonzo, E., Cassese, F.P., D'Isanto, T. (2019). Principles of adaptation of the rules for disabled athletes for an inclusion sport, Journal of Human Sport and Exercise, 14 (Proc2), pp. S215-S220. https://doi.org/10.14198/ihse.2019.14.Proc2.08

Panfil, R., \& Mazur, L. (2018). Operative game monitoring as a fundamental for a football players efficiency evaluation. Quality in Sport, 3(4), 69-83. https://doi.org/10.12775/QS.2017.024

Partington, M., \& Cushion, C. (2013). An investigation of the practice activities and coaching behaviors of professional top-level youth soccer coaches. Scandinavian journal of medicine \& science in sports, 23(3), 374-382. https://doi.org/10.1111/j.1600-0838.2011.01383.x 
Raiola, G., Altavilla, G. (2020) Testing motor skills, general and special coordinative, in young soccer, Journal of Human Sport and Exercise, 15 (Proc2), pp. S206-S212. https://doi.org/10.14198/ihse.2020.15.Proc2.11

Raiola, G., Esposito, G., Sgrò, F. (2020) The formative value of soccer rules,Journal of Human Sport and Exercise, 15, pp. S656-S663. https://doi.org/10.14198/ihse.2020.15.Proc3.18

Raiola, G., Tafuri, D. (2015) Pilot work on training for quantitative aspects of performance [Pilot studija treninga za kvantitativne aspekte učinka izvedbe], Sport Science, 8 (2), pp. 90-93.

Raiola, G., Tafuri, D. (2015) Assessment and periodization in amateur soccer team [Procjena i periodizacija u amaterskoj nogometnoj momčadi], Sport Science, 8, pp. 26-29.

Rizvandi, A., Taghipour Gharbi, M., Esmaeili, M., \& Ashraf Ganjoee, F. (2019). The Evaluation of Performance Indicators of Coaches in Football Development. Journal of Humanities Insights, 3(04), 248-254.

Rosch, D., Hodgson, R., Peterson, L., Graf-Baumann, T., Junge, A., Chomiak, J., \& Dvorak, J. (2000). Assessment and evaluation of football performance. The American journal of sports medicine, 28(5_suppl), 29-39. https://doi.org/10.1177/28.suppl_5.s-29

Turs, D., Napolitano, S., Polidoro, L., Raiola, G. (2013) Video analysis as an instrument in juvenile soccer training, Journal of Human Sport and Exercise, 8 (3 Proc), pp. S688-S693. https://doi.org/10.4100/ihse.2013.8.Proc3.15 